\title{
NIGHT TIME LIGHT SATELLITE DATA FOR EVALUATING THE SOCIOECONOMICS IN CENTRAL ASIA
}

\author{
Shuang $\mathrm{Li}^{\mathrm{a}}$, Tongyao Zhang ${ }^{\mathrm{a}}$, Zhiyu Yang ${ }^{\mathrm{a}}, \mathrm{Xi} \mathrm{Li}^{\mathrm{b}}$, Huimin $\mathrm{Xu}^{\mathrm{c}, *}$ \\ ${ }^{a}$ School of Remote Sensing and Information Engineering, Wuhan University, 430079WuhanChina -2014301630041@whu.edu.cn \\ ${ }^{\mathrm{b}}$ State Key Laboratory of Information Engineering in Surveying, Mapping and Remote Sensing, Wuhan University, \\ 430079WuhanChina - li_rs@163.com \\ ${ }^{c}$ School of Economics, Wuhan Donghu University, Wuhan, China -xuhuimin1985_2008@163.com
}

Commission VI, WG VI/4

KEY WORDS: Night Light, Remote Sensing, Central Asia, Laws of Social and Economic Development

\begin{abstract}
:
Using nighttime lights data combined with LandScan population counts and socioeconomic statistics, dynamic change was monitored in the social economy of the five countries in Central Asia, from 1993 to 2012. In addition, the spatial pattern of regional historical development was analyzed, using this data. The countries included in this study were Kazakhstan, Kyrgyzstan, Tajikistan, Uzbekistan and Turkmenistan. The economic development in these five Central Asian countries, the movement of the economic center, the distribution of poor areas and the night light development index (NLDI) were studied at a relatively fine spatial scale. In addition, we studied the relationship between the per capita lighting and per capita GDP at the national scale, finding that the per capital lighting correlated with per capita GDP. The results of this study reflect the socioeconomic development of Central Asia but more importantly, show that nighttime light satellite images are an effective tool for monitoring spatial and temporal social economic parameters.
\end{abstract}

\section{INTRODUCTION}

"The Belt and Road Initiative" is a vital strategic concept in China. There are more than sixty countries and more than four billion people along the route of "The Belt and Road Initiative". The five countries in Central Asia: Kazakhstan, Kyrgyzstan, Tajikistan, Uzbekistan, and Turkmenistan, are all within the Silk Road Economic Zone. However, these five inland countries lack social economic survey data. Even when country scale social economic data can be found, the availability of socioeconomic data for sub national scale is quite limited (Propastin et al, 2012).

Nighttime light remote sensing refers to the process of access to urban lighting, ship lighting, natural light flares, and other kinds of visible light at night under the cloudless conditions ( $\mathrm{Li}$ et al, 2015). The American Defense Meteorological Satellite Program (DMSP) provides a nighttime light product, which is the beginning of the study of nighttime light remote sensing. The DMSP OLS data covers from 1992 until the present, and is available for civilian use. Due to the direct correlation between nighttime lights and human activities, the scope and intensity of the night light can reflect the prosperity of the region and economic scale.

Nighttime light remote sensing is widely used in the fields of social economic estimation, regional development research, and major event evaluation. Elvidge et al. (1997) studied the relationship between the area of nighttime light and the Gross Domestic Product (GDP), the regression coefficient was found to be 0.97. Elvidge et al. (2012) measured the Global internal development imbalances (i.e. Spatial Gini Index) by the difference between nighttime light distribution and population distribution, finding that Singapore, Puerto Rico, and the
United States has the minimum NLDI, while the Kiribati, Papua New Guinea and Solomon islands had the maximum. Li et al. (2015) evaluated the inequality of social public services at different administrative scales in China. Elvidge et al. (2009) viewed the ratio of the nighttime light data and the demographic data as a measure of poverty. This measure is aggregated to the national scale to get a global grid and administrative poverty index. The global poverty was estimated to be 2.2 billion, which is closed to 2.6 billion provided by the World Bank.

Although nighttime light remote sensing technology has been applied in many countries in the world, it is rarely used in Central Asian countries. Propastin et al. (2012) analyzed the socioeconomic dynamics of Kazakhstan during the period of 1994-2009 by using DMSP/OLS remote sensing images, focusing on analysis of the urbanization process. This study is a start of nighttime lights used in Central Asia. However, the socioeconomic was not included in this study.

In this paper, the temporal and spatial pattern of regional historical development and socioeconomic dynamic in Central Asia were monitored and analyzed using a combination of remote sensing images and social economic statistical data.

\section{DATA AND PREPROCESSING}

\subsection{Study area and data}

Our study area contains five Central Asian countries: Kazakhstan, Kyrgyzstan, Tajikistan, Uzbekistan, and Turkmenistan. Vector data representing the administrative divisions of the five countries are shown in Figure 1.

\footnotetext{
* Corresponding author
} 


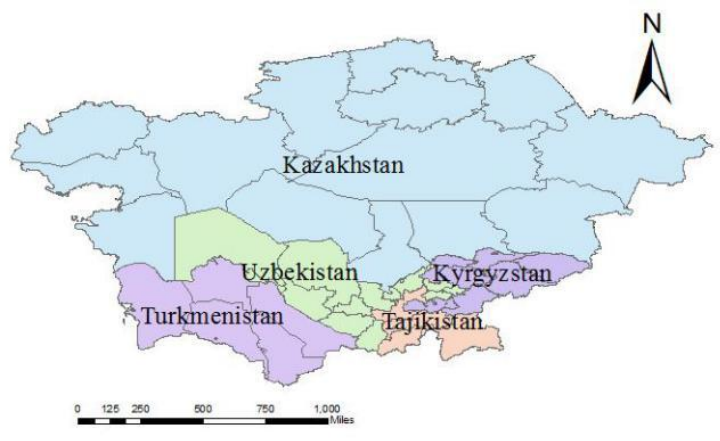

Figure 1. The distribution of the prefectural regions of the five Central Asian countries

DMSP-OLS data: The OLS sensor, equipped with DMSP (the Defense Meteorological Satellite Program) provides a new tool for large-scale urbanization research. The OLS sensor can work at night to detect the city lights and even small-scale residential, traffic, and other low-intensity lights. The National Geophysical Data Center (NGDC) provides long-term DMSP data from 1992 to the present. To get a consistent night time light time series, cloudless and geometrically corrected data was downloaded from NGDC(The National Geophysical Data Center) and calibrated using the calibration model proposed by Zhang et al. (2016). The data for the five Central Asian countries in 1993 and 2012 are shown in Figure 2. The value of each pixel is the annual average data. There are two sets of data independently observed by two satellites each year. All the nighttime lights data used in this study had a spatial resolution of $1 \mathrm{~km}$ and were projected to the Asia_North_Albers_Equal_Area_Conic Projection.

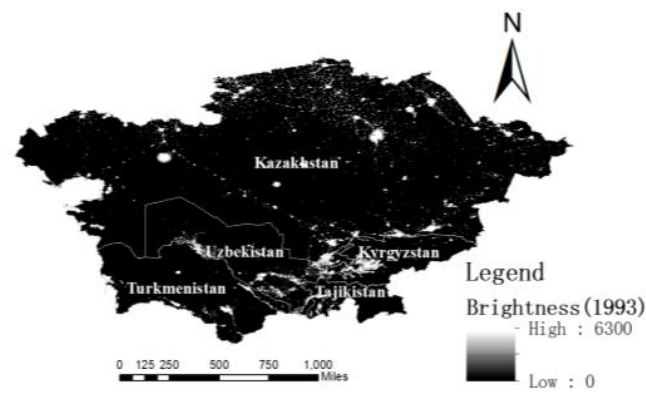

(a)

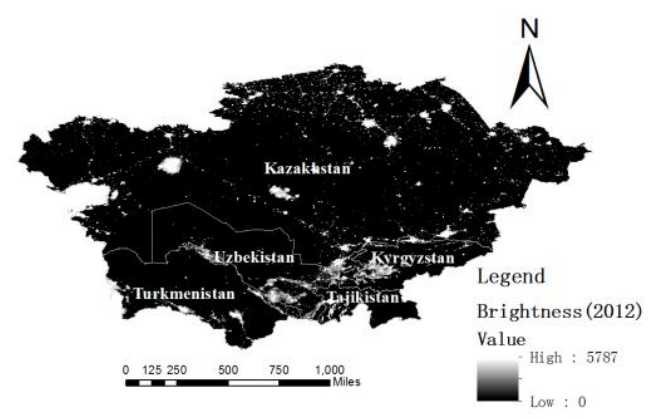

(b)

Figure 2. (a) The DMSP/OLS night light imagery of the five Central Asian countries for 1993; (b) The DMSP/OLS nighttime light imagery from the five Central Asian countries for 2012

LandScan: The LandScan data set is a global population database compiled on a 30"x30" latitude/longitude grid. Census counts at the sub-national level were apportioned to each grid cell based on likelihood coefficients, based on land cover, slope, road proximity, high-resolution imagery, and other data sets. The LandScan data set was developed as part of Oak Ridge National Laboratory (ORNL) Global Population Project for estimating ambient populations at risk (osti, 2017).

GDP: Gross Domestic Product (GDP) is the market value of all final products and services produced by a resident or unit of a country, or a region over a time-period. GDP is the core indicator of national economic accounting, but also an important measure of the overall economic situation of a country or region (National Bureau of Statistics of People's Republic of China, 2017).

\subsection{Removal of gas flaring}

There are a number of oil wells and natural gas wells in the Central Asian region. These light sources and urban night lighting are fundamentally different. In order to study the relationship between the changing trends in light and economic development, it is necessary to remove the interference from oil and gas wells. Oil and gas wells found in the nighttime light imagery are shown in Figure 3.

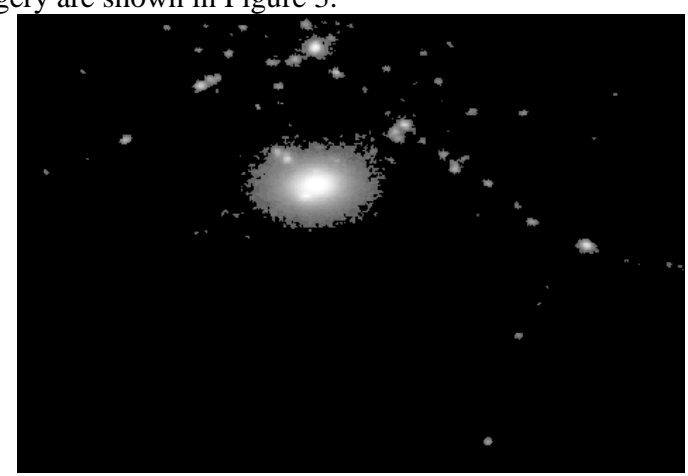

Figure 3. Oil and gas wells in the nighttime light imagery

In this paper, the global urban area mask products provided by the University of Wisconsin were used to remove the natural gas combustion light sources while retaining urban lighting information, to obtain the Central Asian city lighting imagery. In the original light image, urban lighting usually shows up as a central radial form, while burning oil and gas wells are elliptical, displaying characteristics typical of dispersion. Referring to the distribution of oil and gas wells in Central Asia from the ESA website (Figure 4) and global land cover map (Figure 5), the urban area was identified and used to create polygons in ARCGIS. The mask tool in ENVI was applied to mask the original light image.

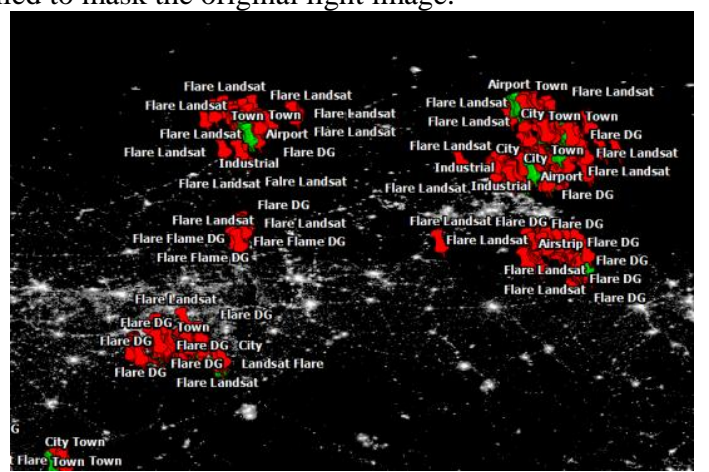

Figure 4. The possible location of the oil and gas wells marked by ESA 


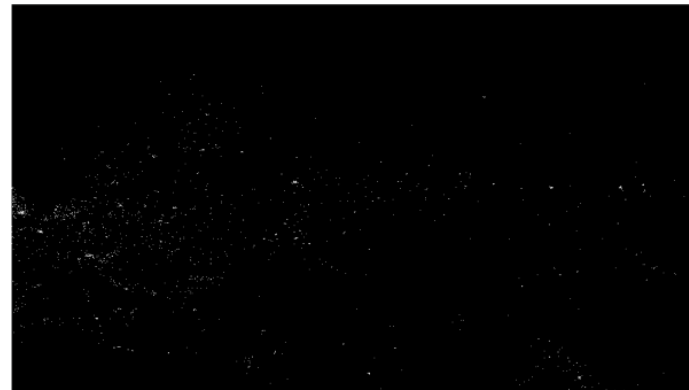

Figure 5. The urban part of the global land cover map

\section{METHODS}

Nighttime light images were used to monitor the socioeconomic of the Central Asian area, including economic development and shifts in the economic center. Combining the LandScan data set and social economic survey data, the spatial temporal pattern of regional development, the distribution of poor areas, and regional development imbalances were analyzed. In addition, the relationship between per capita GDP and per capita lighting was also explored.

\subsection{Economic development analysis}

Nighttime lights reflect socioeconomic development. The more developed the country, the more nighttime lights. In order to estimate socioeconomic change, the change rate of night lighting from 1993 to 2012 was calculated. To avoid the effects of anomalies and noise, we used five years as a unit to divide the 1993-2012 into four time -periods, namely: 1993-1997, 1998-2002, 2003-2007, and 2008-2012.

$$
C R=\frac{T L_{i+1}-T L_{i}}{T L_{i}}
$$

$$
\begin{array}{ll}
\text { where } & \mathrm{i}=[1993-1997,1998-2002,2003-2007,2008-2012] \\
& T L=\text { total lighting } \\
& C R=\text { change rate }
\end{array}
$$

\subsection{The shift of economic center}

The distribution of nighttime lights reflects the uneven distribution of economic activity across different regions, while the center of lights is an indication of the economic center of a region. The standard deviation ellipse analysis in ARCGIS software was employed to locate the center of the night light distribution.

\subsection{Lighting parameters related to per capita GDP}

The total amount of nighttime light is a reflection of the total GDP. To estimate per capita GDP and per capita lighting, we used the economic statistics of the five countries in Central Asia for 1993 -2012, which include the capita GDP and total population of each country (ASIAN DEVELOPMENT BANK, 2017). The total amount of light in the five countries was calculated from the DMSP data and then divided by the total population to get the per capita lighting for each country. A best-fit regression was used to analyze the correction between the per capita GDP and per capita lighting in the past 20 years of each country.

\subsection{The distribution of poor areas}

The per capita lighting was chosen to reflect the distribution of poor areas. The population data came from LandScan 2013, and data of nighttime lights came from DMSP 2012. The population data of 2013 was used to replace the data for 2012, since the population of the Central Asian countries did not change much over one year.

\subsection{Measure of regional development inequality}

NLDI (nighttime light development index) is based on the concept that the regional development inequality is high if a minority of residents lives in an area with the majority of nighttime lights (Elvidge et al, 2012). In this index, the value of NLDI ranges between 0 and 1 , the higher the value, the more unequal the area. The regions with zero population were excluded. A Lorenz curve (Figure 6) was drawn to calculate the NLDI value as follows

$$
N L D I=\frac{S_{B}}{S_{C}}=\frac{\left(S_{C}-S_{A}\right)}{S_{C}}
$$

where $S_{A}, S_{B}$ and $S_{C}=$ areas of A,B and C

Figure 7 shows an example for Andijon Uzbekistan.

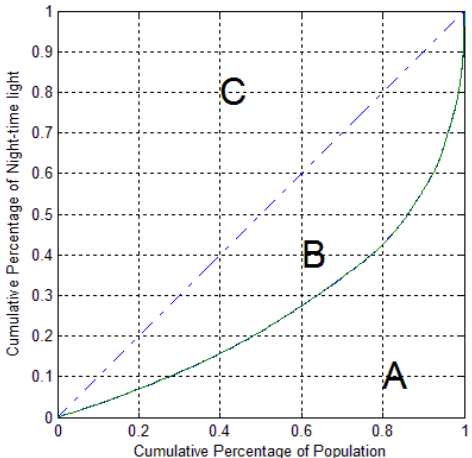

Figure 6. The Lorenz curve and calculation of NLDI

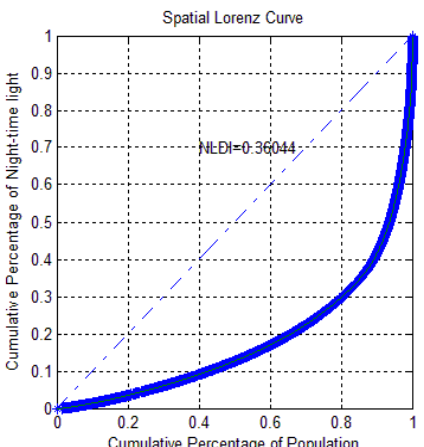

Figure 7. The Lorenz curve and NLDI for the State of Andijon, Uzbekistan

\section{RESULTS AND DISCUSSION}

\subsection{Change of aggregate socioeconomic activity}

The rate of night lighting change was calculated as follows and the results are shown in Figure 8. 


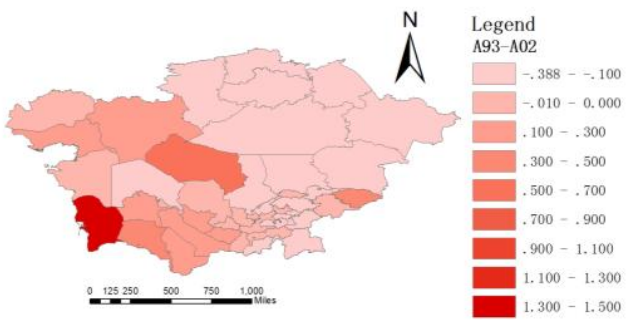

(a)

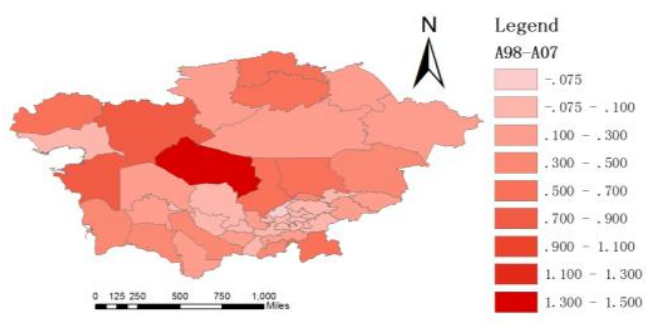

(b)

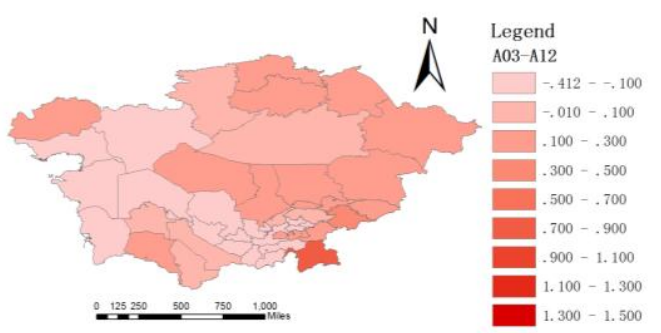

(c)

Figure 8. Change rate of night lighting (a)1993-1997; (b)19982002; (c)2003-2007

The aggregate socioeconomic activity evident in the total amount of light in each period showed that from 1993 to 2012, Kazakhstan and Turkmenistan experienced a substantial increase in socioeconomic development then remained stable, while for the other countries, the change in the range of aggregate socioeconomic activity is small.

\subsection{Analysis of the shift of economic center}

The mean centers of standard deviation ellipse in the 20 years (1993-2012) were drawn in Figure 9 to show the shift of economic centers.

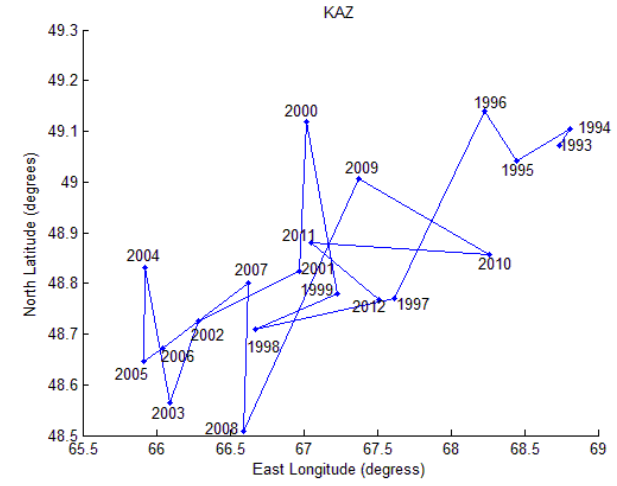

(a)

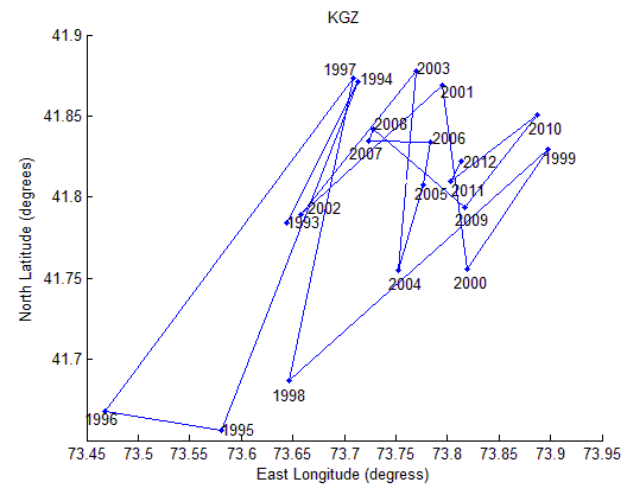

(b)

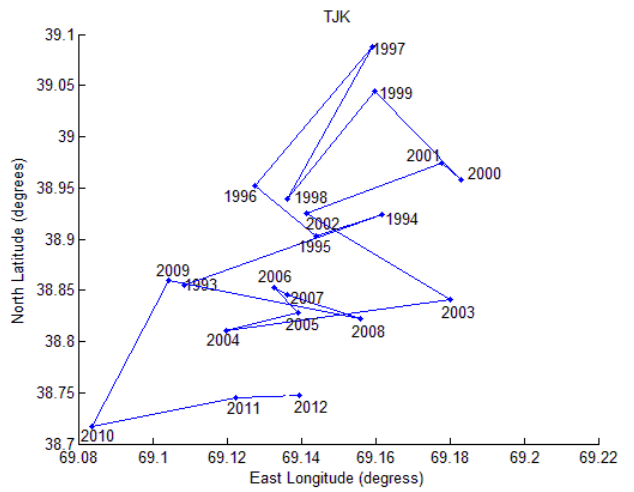

(c)

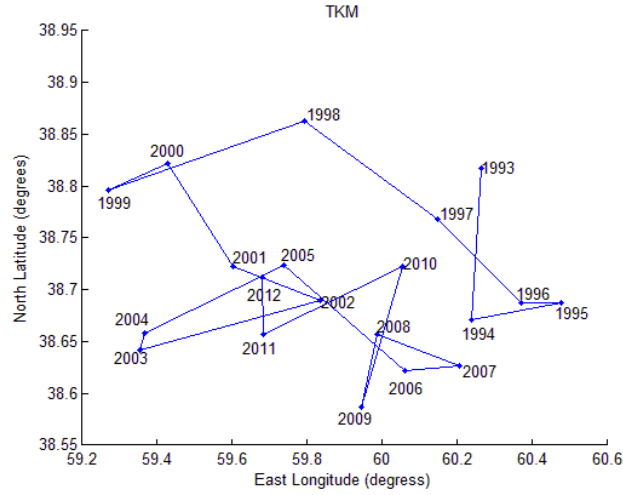

(d)

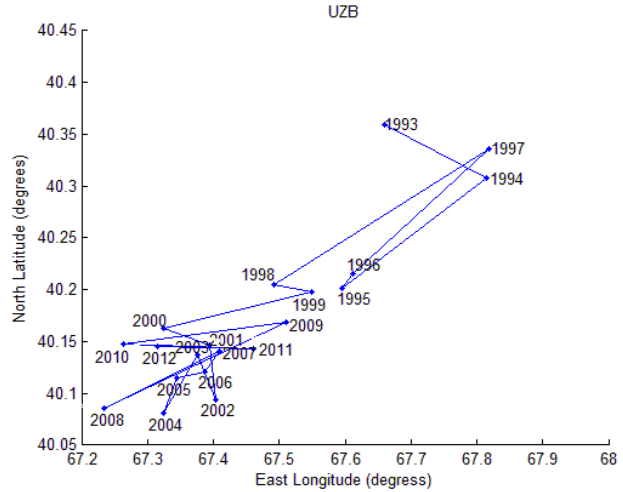

(e)

Figure 9. The shift in five countries' economic centers from 1993-2012 (a) Kazakhstan, (b) Kyrgyzstan, (c) Tajikistan, (d) Turkmenistan, (e) Uzbekistan

It can be seen that in Kazakhstan, the mean center of the standard deviation ellipse moved to the west from 1993 to 2006, and moved eastward from 2007-2012. In Kyrgyzstan, the mean center of the standard deviation ellipse moved north and south, 
while from 2003-2012, it moved slightly eastward. In Tajikistan, the mean center of the standard deviation ellipse moved north from 1993 to 1997, and then moved south from 1998 to 2012. In Turkmenistan, the mean center of the standard deviation ellipse moved westward from 1993-1999, and eastward from 2000 to 2007, and then slightly westward from 2001 to 2012. In Uzbekistan, the mean center of the standard deviation ellipse moved to the southwest, then from 2001 to 2012, it moved slightly north and south.

At the end of 1997, the capital of Kazakhstan moved from Almaty to Astana, which is from the southeast to central. The shift of economic relate to the capital movement. The movement of Kyrgyzstan economic center maybe related to the political environment, but the economic center still lies in the north, due to the economic differences between the north and the south. The North-South movement of the Tajikistan economic center is linked to infrastructure projects, such as gas pipelines. The economic movement of Turkmenistan probably be related to the closure and opening of natural gas pipelines. The movement of the Uzbekistan economic center to the southwest maybe related to the exploitation of resources, such as oil fields.

\subsection{Relationship between lighting parameters and per capita GDP}

The results of the best-fit regression analysis of the per capita GDP and per capita lighting in the past 20 years of each country showed that per capita GDP and per capita lighting was generally correlated but weak for Kazakhstan (Figure 10). It should be noticed that the same conclusion can be drawn for other models since the scatter plots show the correlation between per capita GDP and per capita lighting.

KAZ

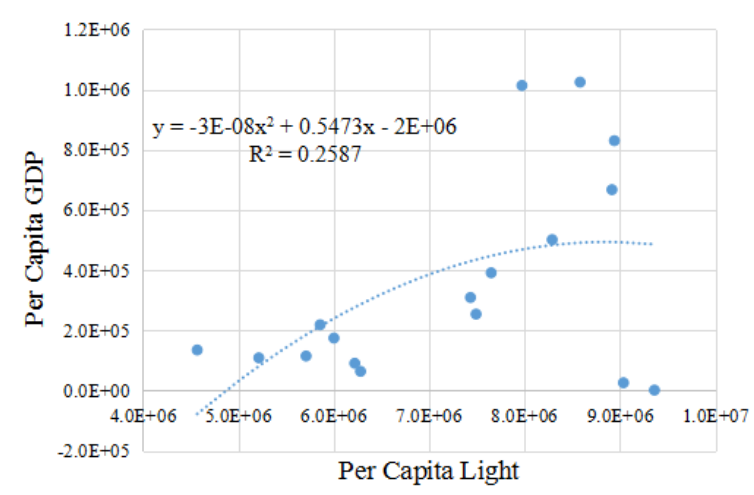

(a)

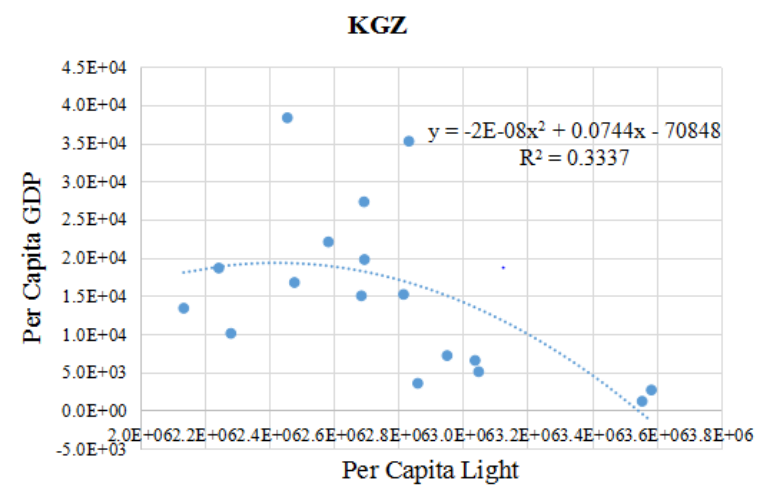

(b)

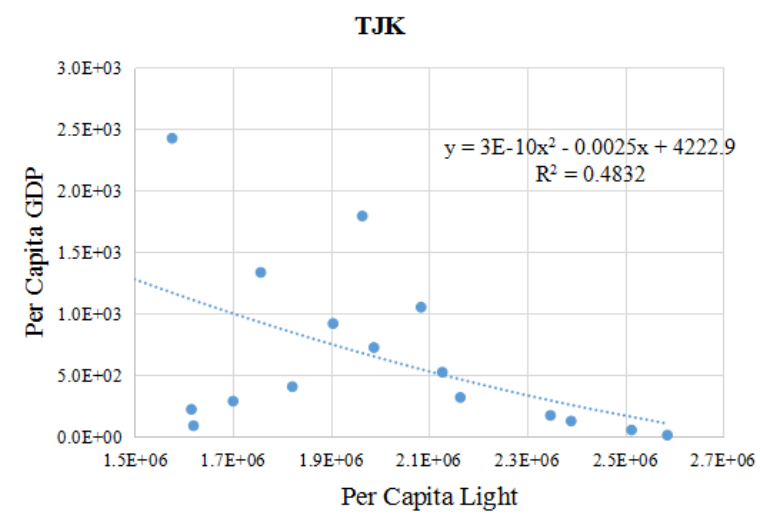

(c)

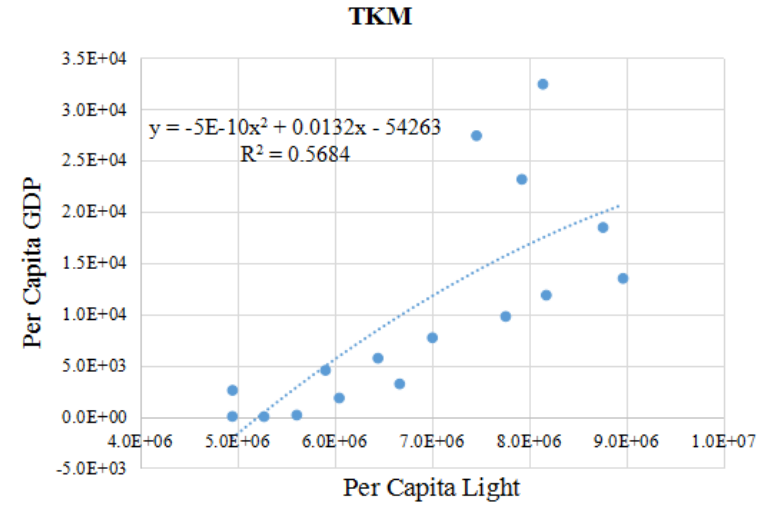

(d)

UZB

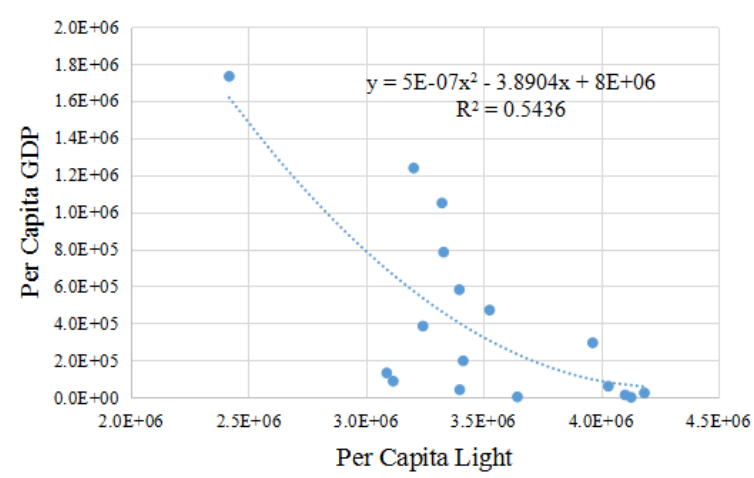

(e)

Figure 10. The best-fit regression results of per capita GDP and per capita lighting for five counties (a) Kazakhstan, (b) Kyrgyzstan, (c) Tajikistan, (d) Turkmenistan, (e) Uzbekistan

\subsection{Analysis of poor area distribution} 11.

The State level distribution of poor areas is shown in Figure 


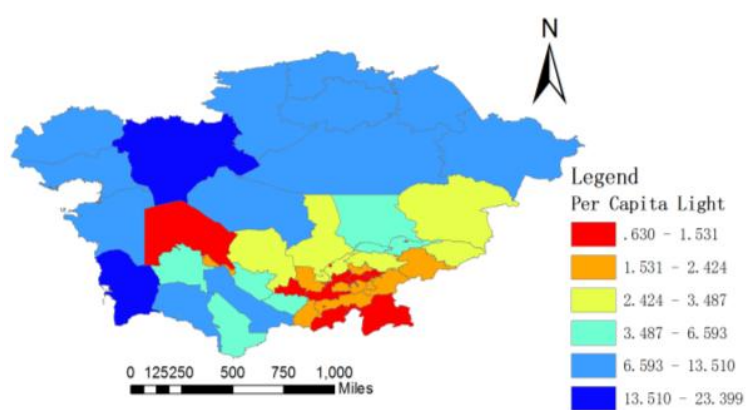

Figure 11. The distribution of per capita lighting

In terms of the distribution of per capita lighting, the areas with low values are concentrated in the southeastern region, including Tajikistan, southern Kyrgyzstan, and northwestern, southern, and central Uzbekistan. A comparison of the GDP of the five Central Asian countries and per capita nighttime lights showed that areas with little per capita lighting were the poor areas, confirming that the total amount of nighttime lights reflects the pattern of uneven development and poor areas, to a certain extent.

\subsection{Regional development inequality measurement}

The NLDI values were used to measure regional inequality. The NLDI values of five Central Asian countries were divided into six grades as shown in Figure 12. A frequency histogram was drawn as shown in Figure 13.

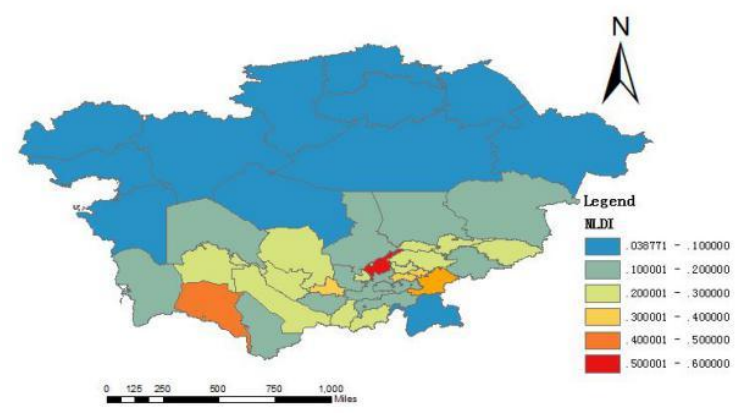

Figure 12. The NLDI values for the five Central Asian countries Frequency Distribution

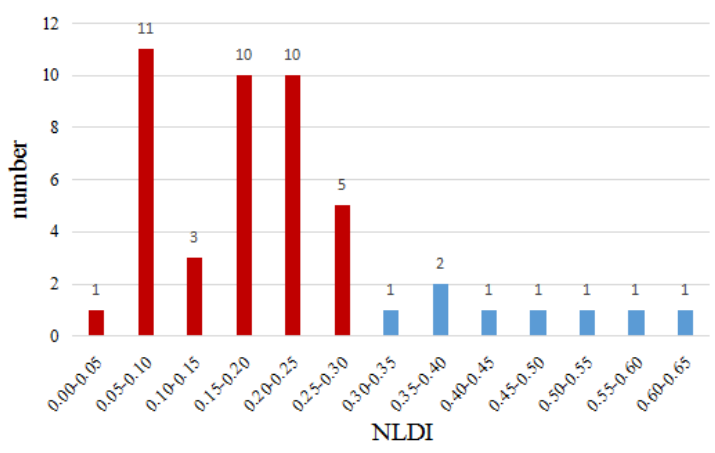

Figure 13. Frequency distribution of NLDI

As seen in Figure 12, Kazakhstan and the eastern part of Kyrgyzstan have the minimum NLDI value, while Uzbekistan's capital Tashkent has the highest value, followed by Turkmenistan's Ahhal. However, the development of most states in Central Asia is balanced, as the frequency distribution in Figure 13 shows.

\section{CONCLUSIONS}

Central Asia occupies an important geographical position in the "The Belt and Road Initiative" strategic concept of China. However, the socioeconomic data for this area is quite limited with almost no sub-national socioeconomic data. This paper use long time series night light data (DMSP) combined with population data (LandScan) to study social economic conditions in the five Central Asia countries, including analysis of economic development, the shift of economic centers, the distribution of poor areas and regional development inequality. We found per capita lighting is related to per capita GDP. The results of this exploratory study can help us know more about socioeconomic of the five Central Asian countries, and thus contribute to the "The Belt and Road Initiative".

\section{ACKNOWLEDGEMENTS}

The authors are grateful for the language suggestions from Mr. Stephen C. McClure from the State Key Laboratory of Information Engineering in Surveying, Mapping and Remote Sensing. This research was supported by Key Laboratory of Spatial Data Mining \& Information Sharing of Ministry of Education, Fuzhou University: [Grant Number 2016LSDMIS03], the Fundamental Research Funds for the Central Universities: [Grant Number 2042016kf0162], Natural Science Foundation of Hubei Province: [Grant Number 2014CFB726].

\section{REFERENCES}

ASIAN DEVELOPMENT BANK, 2017. "Key Indicators for Asiaand the Pacific 2010", https://www.adb.org/publications/k ey--indicators-asia-and-pacific-2010 (15 Jan. 2017).

Elvidge, C. D., Baugh, K. E., Anderson, S. J., Sutton, P. C., \& Ghosh, T., 2012. The night light development index (NLDI): a spatially explicit measure of human development from satellite data. Social Geography \& Discussions, 7(1), 23-35.

Elvidge,C. D., Baugh, K. E., Kihn, E. A., Kroehl, H. W., Davis, E. R., \&Davis, C. W., 1997. Relation between satellite observed visible-near infrared emissions, population, economic activity and electric power consumption. International Journal of Remote Sensing, 18(6), 1373-1379.

Elvidge, C. D., Sutton, P. C., Ghosh, T., Tuttle, B. T., Baugh, K. E., \& Bhaduri, B., et al., 2009. A global poverty map derived from satellite data. Computers \& Geosciences, 35(8), 16521660 .

Elvidge, C. D., Ziskin, D., Baugh, K. E., Tuttle, B. T., Ghosh, T., \& Pack, D. W., et al., 2009. A fifteen year record of global natural gas flaring derived from satellite data. Energies, 2(3), 595-622.

Energy information administration, 2017. "Energy Information Administration homepage", http://www.eiA.doe.gov (4 Mar. 2017).

Li, D., \& Li, X., 2015. An overview on data mining of nighttime light remote sensing. Acta Geodaetica Et Cartographica Sinica, 44(6), 591-601.

National Bureau of Statics of the People's Republic of China, 2017. "China's GDP (gross domestic product) in the first quarter of 2015 preliminary accounting situation", 
http://www.stats.gov.cn/tjsj/zxfb/20150416_713042.html(2Mar. 2017.

Pavel Propastin, \& Martin Kappas., 2012. Assessing satelliteobserved nighttime lights for monitoring socioeconomic parameters in the republic of kazakhstan. Giscience \& Remote Sensing, 49(4), 538-557.

U.S. Department of ENERGY 2017. "LandScan 2014 highresolution global population data set", http://www.osti.gov (12 Apr. 2017).

Xu, H., Yang, H., Li, X., Jin, H., \& Li, D., 2015. Multi-scale measurement of regional inequality in mainland china during 2005-2010 using dmsp/ols night light imagery and population density grid data. Sustainability, 7(10), 13469-13499.

Zhang, Q., Pandey, B., \& Seto, K. C., 2016. A robust method to generate a consistent time series from dmsp/ols nighttime light data.IEEE Transactions on Geoscience \& Remote Sensing, 54(10), 5821-5831. 